SCIENTIFIC REPORT

\title{
Tamponade efficiency of perfluorohexyloctane and silicone oil solutions in a model eye chamber
}

C Wetterqvist, D Wong, R Williams, T Stappler, E Herbert, S Freeburn

Br J Ophthalmol 2004;88:692-696. doi: 10.1136/bjo.2003.024737

Background/aim: As no single tamponade agent yet fulfils all the requirements of a long term inferior tamponade, attempts have been made to mix tamponade materials. This study investigated perfluorohexyloctane $\left(\mathrm{F}_{6} \mathrm{H}_{8}\right)$ and silicone oil solutions designed to take advantage of the high specific gravity and interfacial tension of the $\mathrm{F}_{6} \mathrm{H}_{8}$ and the high viscosity of silicone oil.

Methods: Solutions of three different densities were examined $\left(1.01,1.03\right.$ and $\left.1.06 \mathrm{~g} / \mathrm{cm}^{3}\right)$ inside transparent chambers made of surface modified poly(methylmethacrylate) (PMMA).

Results: Compared to $\mathrm{F}_{6} \mathrm{H}_{8}$, the solutions had poorer contact with hydrophilic surface of the chambers. The higher the specific gravity of the solution, the better was the contact. The solution with a specific gravity $1.01 \mathrm{~g} / \mathrm{cm}^{3}$ is probably of no use clinically.

Conclusion: The model eye chamber made of surface modified PMMA is an efficient way of screening and choosing solutions with promising physical properties. Solutions of silicone oil with $\mathrm{F}_{6} \mathrm{H}_{8}$ in other proportions or with other semifluorinated alkanes may be of interest.

$\mathrm{T}$ he treatment of complex retinal detachments using internal tamponade agents produces successful restoration of vision in many cases; however, recurrence rates for retinal detachment could be as high as $10 \%$ to $20 \%,{ }^{1}$ and even higher in the presence of proliferative vitreoretinopathy (PVR). PVR has a propensity to occur in the inferior retina. ${ }^{2}{ }^{3}$ Of the existing tamponade agents, those available for long term tamponade (gas and silicone oil) do not provide good support to the inferior retina and those that do (for example, perfluorocarbon liquids) can only be used intraoperatively or for the short term. ${ }^{4}$ There is a need therefore to develop effective heavier than water agents that can be used for prolonged tamponade.

The effectiveness of an internal tamponade agent relies on its ability to make contact with the internal surface of the vitreous cavity. In the short term, this is controlled by the agent's specific gravity and interfacial tensions. In the longer term, the viscosity of the material is critical to maintaining its integrity and thus reducing dispersion.

In the case of gas or air, the difference in specific gravity between it and water is great. Therefore, small bubbles are rounded and large bubbles have a flat bottomed shape. ${ }^{5}$ This flattening of the bubble increases the tamponade efficiency in that more of the volume contributes towards making contact with the retina. A small bubble of silicone oil is rounded when in contact with water and with the retina because of its hydrophobicity. In the case of silicone oil, however, the specific gravity $\left(0.97 \mathrm{~g} / \mathrm{cm}^{3}\right)$ is close to that of water $(1.0 \mathrm{~g} /$ $\mathrm{cm}^{3}$ ) and therefore, as expected, large bubbles of silicone oil are also rounded because there is little buoyancy to modify its shape. The overall tamponade efficiency is decreased because part of the volume is used to form the meniscus instead of making contact with the retina. ${ }^{6}$ This difference in efficiency between silicone oil and gas is inherent in their physical properties in terms of surface energy and specific gravity, and cannot be modified except perhaps by strategies such as posturing or the use of surgical explants. ${ }^{7}$

The fluorosilicone oils were investigated as potential heavier than water tamponade agents and found to cause inflammatory responses, foreign body reactions, and epiretinal membranes. ${ }^{8}{ }^{9}$ The ocular toxicity of fluorosilicone oils has been attributed to their low molecular weight components. ${ }^{10}$

Recently, semifluorinated alkanes have been introduced as candidate heavier than water tamponade agents. ${ }^{11}$ They have been shown to be inert and non-toxic to cell cultures and well tolerated when used as blood substitutes ${ }^{12}$ and when placed in rabbit eyes for up to 3 months. ${ }^{13}$ Perfluorohexyloctane $\left(\mathrm{F}_{6} \mathrm{H}_{8}\right)$ is one example of a clear, homogeneous, and laser stable fluid. ${ }^{14} \mathrm{~F}_{6} \mathrm{H}_{8}$ is amphiphilic and is soluble in both silicone oils and perfluorocarbon liquids. Clinically $\mathrm{F}_{6} \mathrm{H}_{8}$ was introduced initially as a silicone oil solvent to remove silicone droplets adherent to intraocular lenses. ${ }^{15}{ }^{16}$ It may be useful as an intraoperative tool as well as a long term tamponade. ${ }^{17} 18$ In some cases, however, epiretinal and retrolental membranes were associated with its use as a prolonged tamponade. The membranes showed histological features typical of PVR but, additionally, they also exhibited dense macrophagic infiltrations. ${ }^{19}$ The macrophagic response was thought to be related to the propensity of $\mathrm{F}_{6} \mathrm{H}_{8}$ to emulsify, which in turn was related to the low viscosity of this tamponade agent.

In this study, we investigated whether a mixture of $\mathrm{F}_{6} \mathrm{H}_{8}$ and silicone oil can act as a new heavier than water tamponade agent. By combining the two liquids, the solution takes advantage of the high specific gravity of the $\mathrm{F}_{6} \mathrm{H}_{8}$ and the high viscosity of silicone oil. In the past, we have found that the hydrophilic properties of the retina can be mimicked by surface modified poly(methylmethacrylate) (PMMA). ${ }^{5}$ We have justified its use to construct transparent model eye chambers $^{7}$ that offer the facility to visualise the interactions between varying volumes of different tamponade materials and a hydrophilic surface.

\section{MATERIALS AND METHODS}

Tamponade agents used in the study are shown in table 1. It is sometimes difficult to visualise and photograph the interface between the $\mathrm{F}_{6} \mathrm{H}_{8}$ and the aqueous solution of protein. Therefore, to increase the contrast between the two transparent liquids, we coloured the $\mathrm{F}_{6} \mathrm{H}_{8}$ with a minimal amount of Sudan black and, in some instances, the protein solution with methylene blue. We believe these dyes had a negligible influence on the physical properties of the agents being investigated. 
Table 1 Physical properties of the tamponade agents tested

\begin{tabular}{|c|c|c|c|}
\hline Tamponade agents & $\begin{array}{l}\text { Specific gravity } \\
\left(\mathrm{g} / \mathrm{cm}^{3}\right)\end{array}$ & $\begin{array}{l}\text { Interface tension at } 25^{\circ} \mathrm{C} \\
\text { against water }(\mathrm{mN} / \mathrm{m})\end{array}$ & Viscosity (mPas) \\
\hline $\begin{array}{l}\text { Perfluorooctane } \\
\mathrm{F}_{6} \mathrm{H}_{8} \\
\text { Silicone oil } \\
\text { Silicone oil } \\
\mathrm{F}_{6} \mathrm{H}_{8}-\mathrm{SiO} \text { solution* } \\
\mathrm{F}_{6} \mathrm{H}_{8}-\mathrm{SiO} \text { solution* } \\
\mathrm{F}_{6} \mathrm{H}_{8}-\mathrm{SiO} \text { solution* }\end{array}$ & $\begin{array}{l}1.73 \\
1.35 \\
0.97 \\
0.97 \\
1.01 \\
1.03 \\
1.06\end{array}$ & $\begin{array}{l}55.0 \\
49.1 \\
35.4 \\
35.4 \\
56.25 \\
45.43 \\
40.82\end{array}$ & $\begin{array}{l}1.76 \\
2.5 \\
5000 \\
1000 \\
3167 \\
1948 \\
1387\end{array}$ \\
\hline \multicolumn{4}{|c|}{$\begin{array}{l}{ }^{*} \text { The solutions are made from mixing } \mathrm{F}_{6} \mathrm{H}_{8} \text { with silicone oil. For example, } 1 \text { part by volume of } \mathrm{F} 6 \mathrm{H} 8 \text { in } 3 \text { parts of } \\
\text { silicone oil would give rise to a solution with a specific gravity of }((1 \times 1.35)+(3 \times 0.97)) \div 4=1.06 \text {. Similarly, } 1 \text { part } \\
\text { of } \mathrm{F}_{6} \mathrm{H}_{8} \text { in } 5 \text { parts of silicone oil give a specific gravity of approximately } 1.03 \text { and, lastly, } 1 \text { part of } \mathrm{F} 6 \mathrm{H} 8 \text { in } 9 \text { parts } \\
\text { of silicone gives a solution of specific gravity approximately of } 1.01 \text {. All tamponade agents were provided by } \\
\text { Fluoron, Neu-Ulm, Germany. }\end{array}$} \\
\hline
\end{tabular}

\section{Contact measurements in the rectangular chamber}

A rectangular chamber was manufactured from PMMA. There was a needle port in the bottom of the chamber to allow injection of fluids. The chamber was filled initially with a $1 \%$ bovine albumin solution in phosphate buffered saline (PBS) ( $\mathrm{pH} 7.4$ ). The albumin was allowed to adsorb onto the internal surface of the chamber for 10 minutes. As shown in previous studies ${ }^{5}$ this rendered the surface hydrophilic.

The chamber was held horizontally on an optical bench with a light at one end to provide even illumination and a camera set up at the other end to record the shape and dimensions of the bubble. The spread of the bubbles on the base of the chamber was used as a measure of the surface contact. The height of the bubble was measured to include the effect of buoyancy. Set volumes of $0.07 \mathrm{ml}$ of the test agents were incrementally injected with a manual syringe driver until a volume of $0.42 \mathrm{ml}$ was reached. The bubble was photographed after each addition (fig 1A). The overall procedure was repeated five times for all tested agents after cleaning the chamber with detergent and rinsing with copious amount of water.

The width and height of the bubbles at the plane of contact with the chamber was measured using a graphics software package after enlargement of the digital pictures, and the

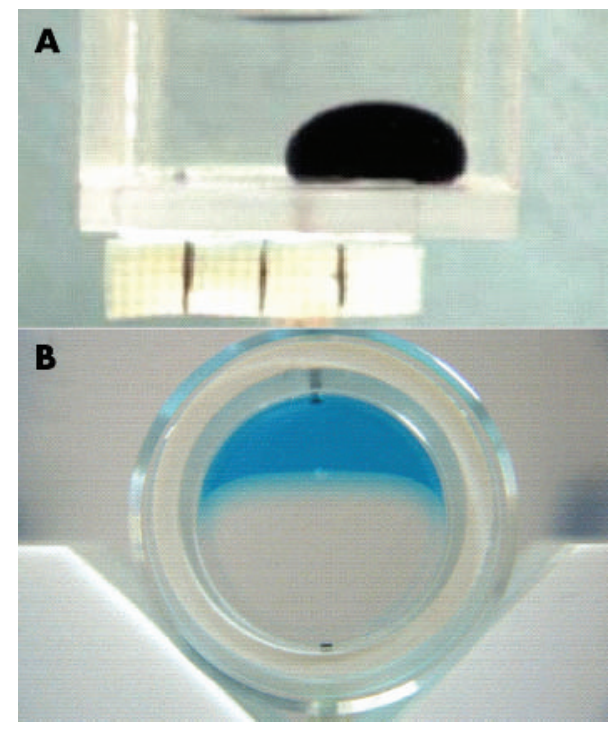

Figure 1 (A) A bubble of $\mathrm{F}_{6} \mathrm{H}_{8}$ coloured with Sudan black in a transparent chamber made of surface modified PMMA and filled with a $1 \%$ bovine albumin solution in phosphate buffered saline. (B) A bubble of $\mathrm{F}_{6} \mathrm{H}_{8}$ in a cylindrical chamber. The aqueous is coloured with methylene blue to enhance the contrast between the buffered saline solution of albumin and the $\mathrm{F}_{6} \mathrm{H}_{8}$. measurements were plotted against the set volumes of the tested liquids. The significance of the data was tested with the SPSS multiple linear regression analyses.

\section{Contact evaluation in the cylindrical model}

For the second part of the study a cylindrical chamber made of PMMA was used. The description and justification for the use of this chamber have been previously reported. ${ }^{72}$ We used three different cylindrical models; (1) without indents, (2) with one indent, and (3) with two indents (to mimic an encircling band). The cylinder was placed on the optical bench and filled with $1 \%$ bovine albumin in PBS as above. The models were filled with increasing volumes of $\mathrm{F}_{6} \mathrm{H}_{8}$ / silicone solutions with densities of 1.01 (A), 1.03 (B), and 1.06 (C) $\mathrm{g} / \mathrm{cm}^{3}$ until a complete fill was achieved. The configuration of the bubble was photographed with a digital camera (fig 1B). Multiple linear regression tests were performed to evaluate the statistical difference between each of the following pairs: $\mathrm{F}_{6} \mathrm{H}_{8} /$ silicone solution A versus $\mathrm{F}_{6} \mathrm{H}_{8}$, solution $B$ versus $\mathrm{F}_{6} \mathrm{H}_{8}$, solution $\mathrm{C}$ versus $\mathrm{F}_{6} \mathrm{H}_{8}$, solution $\mathrm{A}$ versus $B$, solution $A$ versus $C$ and, finally, solution $B$ versus $C$.

\section{RESULTS}

\section{Contact measurements}

The data collected of contact between the test liquid and the surface of the rectangular chamber are presented in figure 2 . The data demonstrate that the bubbles of $\mathrm{F}_{6} \mathrm{H}_{8} /$ silicone solution make less contact - that is, spread less on the surface of the model than bubbles of $\mathrm{F}_{6} \mathrm{H}_{8}$ or perfluoro-octane. With increasing volume, buoyancy plays a part, which is illustrated by figure 3. The height of the bubbles of $\mathrm{F}_{6} \mathrm{H}_{8} /$ silicone solutions was greater than those of pure $\mathrm{F}_{6} \mathrm{H}_{8}$ or perfluorooctane as would be expected by their lower specific gravity of the solutions. Multiple linear regression analysis demonstrated that on average the height of the $\mathrm{F}_{6} \mathrm{H}_{8}$ /silicone solution bubbles was significantly $(\mathrm{p}<0.0001)$ higher than the $\mathrm{F}_{6} \mathrm{H}_{8}$ bubbles and the height of the perfluoro-octane bubbles was significantly $(\mathrm{p}<0.0001)$ lower than the $\mathrm{F}_{6} \mathrm{H}_{8}$. Similarly, the width of the $\mathrm{F}_{6} \mathrm{H}_{8}$ /silicone solution bubbles was significantly $(\mathrm{p}<0.0001)$ lower than the $\mathrm{F}_{6} \mathrm{H}_{8}$ and the width of the perfluoro-octane bubbles was significantly higher than those of $\mathrm{F}_{6} \mathrm{H}_{8}(\mathrm{p}<0.0001)$.

\section{$\mathrm{F}_{6} \mathrm{H}_{8} /$ silicone solutions of different specific gravities in cylinder model}

The images collected from the filling experiments of the three different $\mathrm{F}_{6} \mathrm{H}_{8}$ silicone solutions in the three cylindrical chambers can be used to evaluate the behaviour of the materials qualitatively. Measurement of the height of the bubbles was recorded as a means of quantifying the behaviour of the three $\mathrm{F}_{6} \mathrm{H}_{8} /$ silicone solutions. 


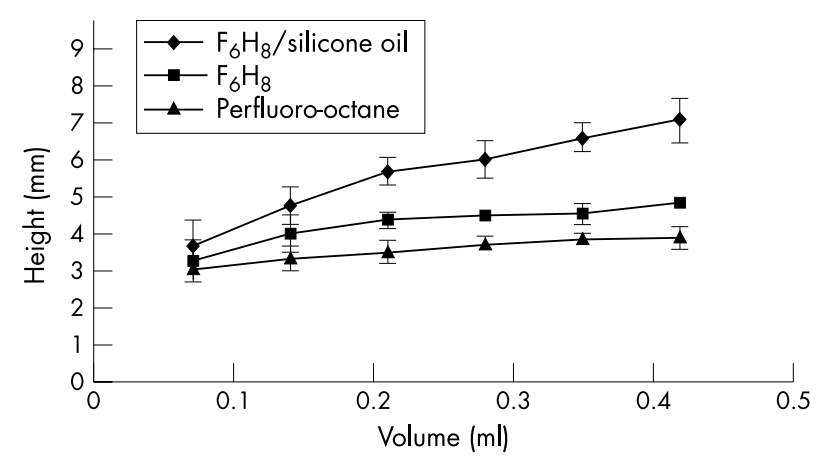

Figure 2 Height of the bubble versus the volume of the bubble inside the chamber. Five readings were obtained for each incremental volume. The height of the $\mathrm{F}_{6} \mathrm{H}_{8} /$ silicone oil solution $\left(1.06 \mathrm{~g} / \mathrm{cm}^{3}\right)$ was significantly different from that of pure $\mathrm{F}_{6} \mathrm{H}_{8}$ and of perfluoro-octane.

Figure 4 shows representative images of $\mathrm{F}_{6} \mathrm{H}_{8}$ and the three $\mathrm{F}_{6} \mathrm{H}_{8} /$ silicone solutions in the cylindrical models. After $2 \mathrm{ml}$ of the tamponade agent had been added it is clearly seen that the difference in specific gravity of the agents influences the height of the bubbles. The height of the bubbles was measured and the data for three replicates at each volume are presented in figure 5. Statistical analysis of these data demonstrate that there is a significant difference between $\mathrm{F}_{6} \mathrm{H}_{8}$ and each $\mathrm{F}_{6} \mathrm{H}_{8} /$ silicone solutions $(\mathrm{p}<0.0001$ in each case), that there is a significant difference between solutions $A$ and $B(p<0.0001)$ and between solutions A and C $(p<0.0001)$ and that there is no significant difference between solutions $\mathrm{B}$ and $\mathrm{C}$ (table 2).

Figures 6A and $B$ show representative images of $\mathrm{F}_{6} \mathrm{H}_{8} /$ silicone solutions $\mathrm{A}$ and $\mathrm{C}$ in the cylindrical model with one indent. These images demonstrate that the indent causes the tamponade bubble to be pushed towards the opposite side of the chamber. The volume added to the chamber was $5 \mathrm{ml}$ in both cases and it can be seen that $\mathrm{F}_{6} \mathrm{H}_{8}$ /silicone solution $\mathrm{A}$ makes contact with the opposite side of the model to a point higher up the chamber wall than $\mathrm{F}_{6} \mathrm{H}_{8}$ /silicone solution $\mathrm{C}$ but that there is a larger region below the indent which is not tamponaded for solution A than solution C.

Figure $6 \mathrm{C}$ and $\mathrm{D}$ show representative images of $5 \mathrm{ml} \mathrm{F}_{6} \mathrm{H}_{8}$ and solution $\mathrm{B}$ in the model chamber with two indents. It is demonstrated that the $\mathrm{F}_{6} \mathrm{H}_{8}$ wraps neatly around the indents whereas solution $\mathrm{B}$ is squeezed causing a reduction in the tamponade effect around the indent but an increase in the effect at the top of the chamber.

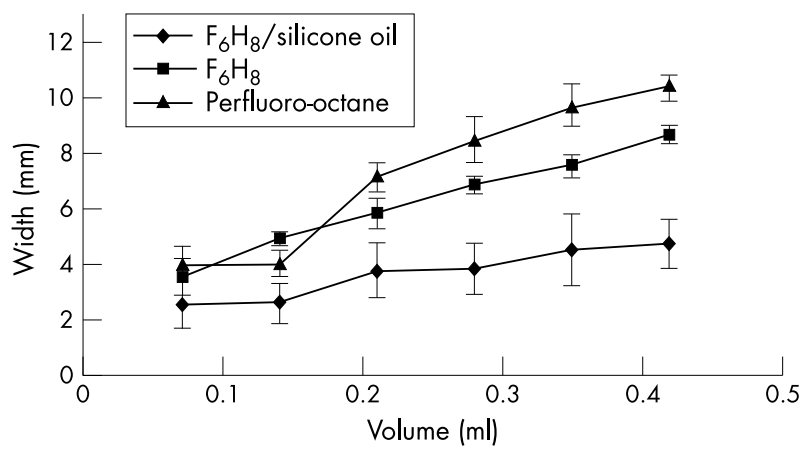

Figure 3 Width of the bubbles against incremental volumes of tamponade agents. The width of the $\mathrm{F}_{6} \mathrm{H}_{8} /$ silicone oil solution $(1.06 \mathrm{~g} /$ $\mathrm{cm}^{3}$ ) was significantly different from that of pure $\mathrm{F}_{6} \mathrm{H}_{8}$ and of perfluorooctane.

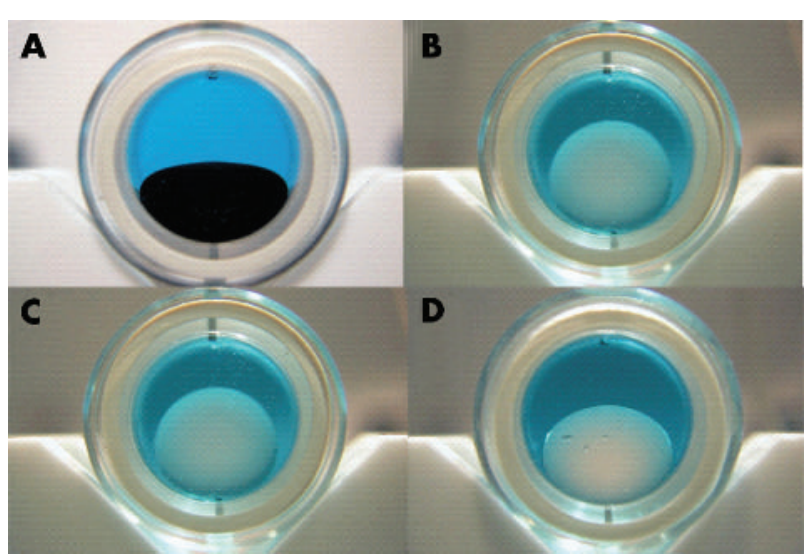

Figure 4 A volume of $2 \mathrm{ml}$ of each tamponade agent: (A) $\mathrm{F}_{6} \mathrm{H}_{8}$, (B) $\mathrm{F}_{6} \mathrm{H}_{8} /$ silicone solution $\mathrm{A}\left(1.01 \mathrm{~g} / \mathrm{cm}^{3}\right)$, (C) solution $\mathrm{B}\left(1.03 \mathrm{~g} / \mathrm{cm}^{3}\right)$, (D) solution $C\left(1.06 \mathrm{~g} / \mathrm{cm}^{3}\right)$.

\section{DISCUSSION}

A tamponade that sinks might be useful in many situations. The indications will include large inferior retinal breaks and cases with PVR, which has a predilection for the inferior retina. Many patients will find it easier to adopt an erect posture than to maintain a prone position for long periods.

The effectiveness of tamponade agents is dependent on three main factors: (1) the interfacial tensions between the retina, the aqueous, and the tamponade agent; (2) the difference in the specific gravity of the agent and the aqueous (buoyancy); (3) the viscosity of the agent. At present, all the agents used have advantages in one property area and disadvantages in another. The question arises as to whether it is possible to combine two tamponade agents to fulfil more of the requirements.

Combining two tamponade agents to produce a new tamponade agent with improved properties is not a new concept. A copolymer of silicone and fluorosilicone oil has been evaluated. By combining the two oils the resultant viscosity was low (175-185 mPas) and the specific gravity was slightly heavier than water (density $1.16 \mathrm{~g} \mathrm{~cm}^{3}$ ). Although the copolymer produced trophic changes in the inferior retina such as thinning or disappearance of the outer plexiform layer in rabbit retina after 6-8 weeks, these trophic changes were much less than those observed with the heavier perfluorotetradecahydrophenanthrene (density $2.03 \mathrm{~g} / \mathrm{cm}^{3}$,

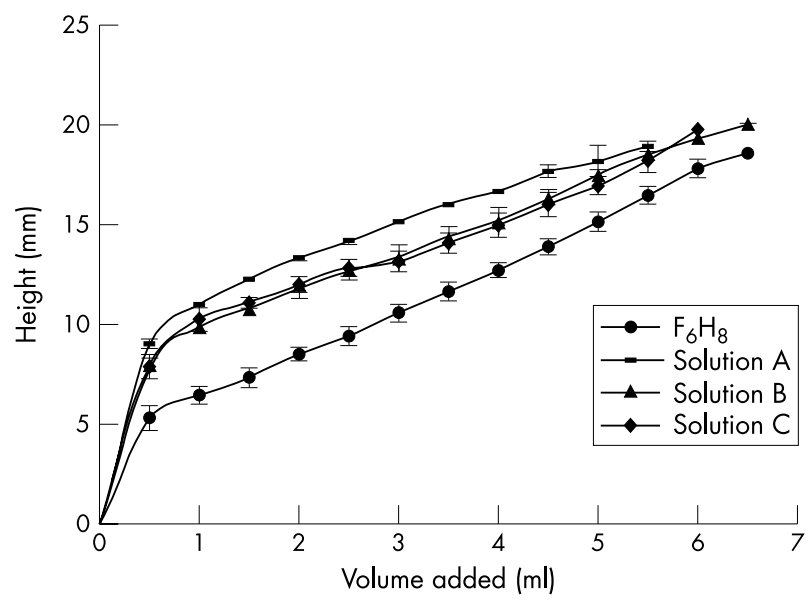

Figure 5 Height measurements of the bubbles of $\mathrm{F}_{6} \mathrm{H}_{8}$ and the $\mathrm{F}_{6} \mathrm{H}_{8} /$ silicone oil solutions $A\left(1.01 \mathrm{~g} / \mathrm{cm}^{3}\right), B\left(1.03 \mathrm{~g} / \mathrm{cm}^{3}\right)$, and $C(1.06 \mathrm{~g} /$ $\mathrm{cm}^{3}$ ). Three measurements were taken at each added volume. 
Table 2 Level of significance when one agent was tested against another using multiple linear regression to find the best fit for a number of parallel lines to the data

\begin{tabular}{lllll}
\hline & $\mathrm{F}_{6} \mathrm{H}_{8}$ & A & B & C \\
\hline $\mathrm{F}_{6} \mathrm{H}_{8}$ & $\mathrm{p}<0.0001$ & $\mathrm{p}<0.0001$ & $\mathrm{p}<0.0001$ & $\mathrm{p}<0.0001$ \\
$\mathrm{~B}$ & $\mathrm{p}<0.0001$ & $\mathrm{p}<0.0001$ & $\mathrm{p}<0.0001$ & $\mathrm{p}=0.7$ \\
$\mathrm{C}$ & $\mathrm{p}<0.0001$ & $\mathrm{p}<0.0001$ & $\mathrm{p}=0.7$ & \\
\hline
\end{tabular}

The equation for best fit for the $\mathrm{F}_{6} \mathrm{H}_{8}$ plot is given as: height $=\left(\right.$ slope $\times$ volume $\left.-\mathrm{F}_{6} \mathrm{H}_{8}\right)+$ intercept.

Similar equation for each of the solutions $A, B$, and $C$ were found and as the lines are parallel, the slopes are the same, but the intercepts are different. SPSS output gives $95 \%$ confidence intervals for difference between the intercepts for $\mathrm{F}_{6} \mathrm{H}_{8}$ and each of the solutions and the $\mathrm{p}$ value for this difference.

$8.03 \mathrm{mPas}$ ), which included thinning and disorganisation of the photoreceptor layer, and migration of the receptor cell nuclei to the photoreceptor layer. ${ }^{21}$ Clearly, moving towards a less heavy internal tamponade agent was useful, but the low viscosity was a major disadvantage. Small droplets ingested by mononuclear cells were found in the vitreous cavity or preretina at 4-6 months in silicone/fluorosilicone copolymer injected eyes. ${ }^{22}$

Kirchhof et al emphasised the importance of displacement of the aqueous milieu from the surface of the retina. ${ }^{18}$ It was for this reason that $\mathrm{F}_{6} \mathrm{H}_{8}$ appeared at first sight to be so attractive. It has a very high interfacial tension with water and made good contact with the retina. This was demonstrated qualitatively in figures $6 \mathrm{C}$ and $\mathrm{D}$. For the same volume of tamponade agent, the $\mathrm{F}_{6} \mathrm{H}_{8}$ made much better contact than silicone oil and $\mathrm{F}_{6} \mathrm{H}_{8}$ is capable of fitting into the recesses above and below the indents. The difference in ability to make contact with a hydrophilic surface between $\mathrm{F}_{6} \mathrm{H}_{8}$ and silicone oil is also confirmed by the data which showed a significant difference in the width and the height of the respective bubbles.

With any tamponade agent, the lower the viscosity, the less mechanical energy is needed to dispersed a large bubble to small droplets. ${ }^{23}$ Small droplets will coalesce into the larger bubbles to achieve lower surface energies unless they are stabilised by surfactants and there are many substances including albumin, phospholipids, and cholesterol inside an eye that can act as emulsifiers. It seemed logical to aim for

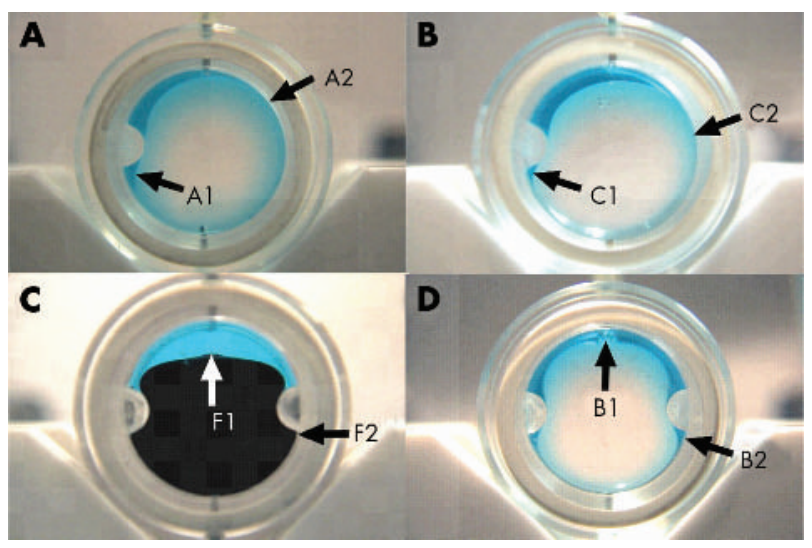

Figure 6 (A, B) Representative images of $5 \mathrm{ml}$ fill of $\mathrm{F}_{6} \mathrm{H}_{8} /$ silicone solutions $A\left(1.01 \mathrm{~g} / \mathrm{cm}^{3}\right)$ and $C\left(1.06 \mathrm{~g} / \mathrm{cm}^{3}\right)$ in the cylindrical mode chamber with one indent. Arrow $\mathrm{Cl}$ showed that there was aqueous below the indent which is even more marked at $\mathrm{Al}$. Solution $\mathrm{A}$ makes contact with the opposite side of the model to a point higher up the chamber wall (arrow A2) than solution $\mathrm{C}$ (arrow C2). (C, D)

Representative images of $5 \mathrm{ml}$ fill of $\mathrm{F}_{6} \mathrm{H}_{8}$ and $\mathrm{F}_{6} \mathrm{H}_{8}$ /silicone solution $B$ $\left(1.03 \mathrm{~g} / \mathrm{cm}^{3}\right)$ in the cylindrical model with two indents. Arrow F1 points to the $\mathrm{F}_{6} \mathrm{H}_{8}$ bubble (with Sudan black) which has a flat top surface whereas arrow $B 1$ points to solution $B$ bubble which has a rounded top surface. Arrow F2 shows that $\mathrm{F}_{6} \mathrm{H}_{8}$ fits into the recess below the indent whereas B2 shows clearly that there is aqueous below the indent. high viscosity by combining silicone oil with $\mathrm{F}_{6} \mathrm{H}_{8}$. Although $\mathrm{F}_{6} \mathrm{H}_{8}$ is amphiphilic and although $\mathrm{F}_{6} \mathrm{H}_{8}$ and silicone oil are soluble in one another, the two tamponade agents do not mix readily at room temperature. The solutions are prepared by applying heat and sonication. ${ }^{11}$ There is a limit to the solubility of $\mathrm{F}_{6} \mathrm{H}_{8}$ in silicone oil and this solubility is dependent on the temperature and the viscosity of the silicone oil used. When the solution reaches saturation it may turn turbid. The three $\mathrm{F}_{6} \mathrm{H}_{8} /$ silicone solutions we tested were well within the limits of solubility and their viscosity are high enough to limit their propensity to disperse. One objective in combining the two agents was achieved-namely, high viscosity.

The surface properties of the three $\mathrm{F}_{6} \mathrm{H}_{8} /$ silicone solutions are surprising. We expected the solutions to take on a surface property intermediate to that of their constituents. Instead, the solutions can have interfacial tension with water higher than that of silicone oil and $\mathrm{F}_{6} \mathrm{H}_{8}$. The precise nature of the molecular arrangement of the solution is not known. There is evidence that $\mathrm{F}_{6} \mathrm{H}_{8}$ forms micelles inside the silicone oil (Kim YK, Meinert H. Semifluorinated liquid alkanes and silicone oil (solvent and admixtures), personal communication, Hea-Taml Meeting, Austria; abstract, www.hea-taml. $\operatorname{org} /$ ).

The model chambers showed that the three solutions behave more like silicone rather than $\mathrm{F}_{6} \mathrm{H}_{8}$. The contact with hydrophilic surface of the chamber is poor; the solutions do not fit into the recesses of chambers with indents. This is easily seen in figures $6 \mathrm{C}$ and $\mathrm{D}$. The $\mathrm{F}_{6} \mathrm{H}_{8} /$ silicone solution bubbles are much more rounded when compared to $\mathrm{F}_{6} \mathrm{H}_{8}$, the contrast being particularly marked for the $1.01 \mathrm{~g} / \mathrm{cm}^{3}$ solution. Again the qualitative information is confirmed by the significant differences between the quantitative data (fig 5 and table 2).

The $\mathrm{F}_{6} \mathrm{H}_{8} /$ silicone solutions have provided for the first time a heavier than water tamponade with relatively low specific gravity. Our results showed that a solution of $1.01 \mathrm{~g} / \mathrm{cm}^{3}$ behaved significantly differently from solutions of 1.03 or $1.06 \mathrm{~g} / \mathrm{cm}^{3} \mathrm{~F}_{6} \mathrm{H}_{8} /$ silicone. We concluded that the $1.01 \mathrm{~g} / \mathrm{cm}^{3}$ solution is probably clinically not effective. Although it is possible to create solutions with higher specific gravities $\left(1.10 \mathrm{~g} / \mathrm{cm}^{3}\right.$ or more) by adding more $\mathrm{F}_{6} \mathrm{H}_{8}$ to silicone, the solutions would not be as viscous or as stable (precipitation with low temperatures). We have chosen to use the solution $1.06 \mathrm{~g} / \mathrm{cm}^{3}$ for a multicentre international clinical trial.

\section{ACKNOWLEDGEMENTS}

The authors thank the Fluoron company, Neu-Ulm, Germany, for providing the solutions of $\mathrm{F}_{6} \mathrm{H}_{8}$ in silicone oil and Ian Campbell, Liverpool, for assistance with statistical analysis. The authors have no financial interest in any devices described in this presented study.

\author{
Authors' affiliations \\ E Herbert, T Stappler, D Wong, S Freeburn, Royal Liverpool University \\ Hospital, Prescot Street, Liverpool L7 8XP, UK
}


R Williams, Department of Clinical Engineering, University of Liverpool L69 3BX, UK

C Wetterqvist, Department of Ophthalmology, Orebro University Hospital, Sweden

Correspondence to: David Wong, Royal Liverpool University Hospital, Prescot Street, Liverpool L7 8XP, UK; david.wong@medix-uk.com

Accepted for publication 25 June 2003

\section{REFERENCES}

1 Sullivan PM, Luff AJ, Aylward GW. Results of primary retinal reattachment surgery: a prospective audit. Eye 1997;11(Pt 6):869-71.

2 Singh AK, Michels RG, Glaser BM. Scleral indentation following cryotherapy and repeat cryotherapy enhance release of viable retinal pigment epithelial cells. Retina 1986;6:176-8.

3 Singh AK, Glaser BM, Lemor M, et al. Gravity-dependent distribution of retinal pigment epithelial cells dispersed into the vitreous cavity. Retina 1986;6:77-80.

4 Colthurst MJ, Williams RL, Hiscott PS, et al. Biomaterials used in the posterior segment of the eye. Biomaterials 2000;21:649-65.

5 Fawcett IM, Williams RL, Wong D. Contact angles of substances used for internal tamponade in retinal detachment surgery. Graefes Arch Clin Exp Ophthalmol 1994;232:438-44.

6 Wong D, Lois N. Perfluorocarbons and semifluorinated alkanes. Sem Ophthalmol 2000;15:25-35.

7 Williams R, Wong D. The influence of explants on the physical efficiency of tamponade agents. Graefes Arch Clin Exp Ophthalmol 1999;237:870-4.

8 Petersen J, Ritzau-Tondrow U, Vogel M. [Fluorosilicone oil heavier than water: a new aid in vitreoretinal surgery]. Klin Monatsbl Augenheilkd 1986; 189:228-32.

9 Gabel VP, Kampik A, Gabel C, et al. Silicone oil with high specific gravity for intraocular use. BrJ Ophthalmol 1987:71:262-7.

10 Nakamura K, Refojo MF, Crabtree DV, et al. Ocular toxicity of low-molecularweight components of silicone and fluorosilicone oils. Invest Ophthalmol Vis Sci 1991; 32:3007-20.
11 Meinert H, Roy T. Semifluorinated alkanes-a new class of compounds with outstanding properties for use in ophthalmology. Eur J Ophthalmol 2000;10:189-97.

12 Meinert $\mathrm{H}$, Knoblich A. The use of semifluorinated alkanes in bloodsubstitutes. Biomaterials, Artificial Cells, and Immobilization Biotechnology: Official Journal of the International Society For Artificial Cells and Immobilization Biotechnology 1993;21:583-95.

13 Zeana D, Becker J, Kuckelkorn R, et al. Perfluorohexyloctane as a long-term vitreous tamponade in the experimental animal. Experimental perfluorohexyloctane substitution. Int Ophthalmol 1999;23:17-24.

14 Meinert H, Mader J, Rohlke W, et al. Chemical and physical stability of perfluorocarbons with laser treatment. Eur J Ophthalmol 1995:5:219-24.

15 Dick HB, Augustin AJ. Solvent for removing silicone oil from intraocular lenses: experimental study comparing various biomaterials. J Cataract Refract Surg 2000;26:1667-72.

16 Langefeld S, Kirchhof B, Meinert H, et al. A new way of removing silicone oil from the surface of silicone intraocular lenses. Graefes Arch Clin Exp Ophthalmol 1999;237:201-6.

17 Stefaniotou MI, Aspiotis MV, Kitsos GD, et al. Our experience with perfluorohexyloctane $\left(\mathrm{F}_{6} \mathrm{H}_{8}\right)$ as a temporary endotamponade in vitreoretinal surgery. Eur J Ophthalmol 2002;12:518-22.

18 Kirchhof B, Wong D, Van Meurs J, et al. Use of perfluorohexyloctane as a long-term internal tamponade agent in complicated retinal detachment surgery. Am J Ophthalmol 2002;133:95-101.

19 Hiscott P, Magee RM, Colthurst M, et al. Clinicopathological correlation of epiretinal membranes and posterior lens opacification following perfluorohexyloctane tamponade. Br J Ophthalmol 2001;85:179-83.

20 Wong D, Williams RL, German MJ. Exchange of perfluorodecalin for gas or oil: a model for avoiding slippage. Graefes Arch Clin Expl Ophthalmol 1998;236:234-7.

21 Doi M, Refojo MF. Histopathology of rabbit eyes with intravitreous siliconefluorosilicone copolymer oil. Exp Eye Res 1994:59:737-46.

22 Doi M, Refojo MF. Histopathology of rabbit eyes with silicone-fluorosilicone copolymer oil as six months internal retinal tamponade. Exp Eye Res 1995;61:469-78.

23 Nakamura K, Refojo MF, Crabtree DV. Factors contributing to the emulsification of intraocular silicone and fluorosilicone oils. Invest Ophthalmol Vis Sci 1990;31:647-56. 